work being done by the test development and research office of the school examination department of the University of London. Similar investigations in different subjects are obviously desirable, but will only be instigated if this first operation is considered to be a success.

\section{No Joy for Doctors}

The view that seems to be shared by the British medical and dental professions - that better pay would be a panacea-is strongly but tactfully contested in the latest report of the Review Body on Doctors' and Dentists' Remuneration (HMSO, $6 s .3 d$.), published on May 7. This is the ninth report to appear since the review body was set up in March 1962 to act as mediator-and to some extent pacifier-between the professions and the Government.

It is in fact surprising that the professions have asked for more, because the seventh report of the review body, published only two years ago, recom. mended substantial increases, particularly for general medical practitioners, but also for hospital doctors at all levels. The value of distinction awards for consultants was also increased by approximately 8 per cent, and new net incomes were recommended for dentists. Although the Government decided for reasons of incomes policy to phase the implementation of the review body's recommendations on general medical practitioners, the other recommendations were accepted.

The doctors' representatives have proposed an increase of about 8 per cent for the period from April 1, 1968, to April 1, 1970. They suggest that this is necessary to take account of the rise in the cost of living since the seventh report came out, to reward increased responsibility and workload, and to recognize the manpower situation. They also point out that certain fees or allowances should be brought up to date.

The views of the health departments rarely agree with those of the professions, but the review body has done its best to hold the balance between the two. It therefore suggests that if general practitioners could be encouraged to have practices in relatively unpopular areas by increasing the present allowance by about $£ 100$ a year, this would probably be justified under the "manpower" criterion of the current incomes policy. It also considers that an increase in the allowance of $£ 175$ for pre-entry vocational training might be justified if this acted as an inducement. It proposes that the age limit for general medical practitioners should be increased to 72 , provided that the health departments and the profession's representatives can work out a satisfactory method of establishing the continued ability of the individual. The review body does not agree with the profession's feeling that the fee for a night visit between midnight and $7 \mathrm{a} . \mathrm{m}$. should be increased from the present value of $£ 1$ to $£ 25 s$. and it dismisses the idea of introducing a new fee for night consultation at a doctor's surgery. As far as temporary arrangements for carrying on a practice are concerned, - for example, following the death or retirement of a general practitioner-the review body feels that this is something that should be worked out by the health departments and representatives of the medical profession, and should not simply be compensated for by financial reward.

The report recommends that from April 1, 1968, a new scale for medical assistants and assistant dental surgeons beginning at $£ 1,950$ and rising by 14 annual increments to $£ 3,525$ should come into being. This represents an increase of $5 \cdot 5-8.5$ per cent over previous rates. It also recommends that the weekly or sessional rates for locums in these grades should be raised $t$, $£ 5213 s$. a week or $£ 416 s$. a "notional" half day to correspond with the new scale. Another positive recommendation is that the number, but not the value, of distinction awards for consultants should be increased from a total of 3,370 to 3,580 . The review body agrees with the health departments that lectures to groups of hospital doctors and dentists should attract a fee $(£ 5)$, but only when the lecture is outside the lecturer's own hospital group and in cases where the lecture has to be prepared substantially at home. Small increases in expense allowances for general practitioners are also proposed.

Although the recommendations in this rather negative report will probably disappoint many doctors, they are at least assured that the review body will "not hesitate to recommend an immediate general increase in remuneration" if at any time it considers this to be justified. One thing that is made clear, though, is that the medical and dental professions cannot expect preferential treatment, "and cannot escape the realities of the economic situation or the application of incomes policy".

\section{Preparing for the Eclipse}

Nот only astronomers but also ophthalmologists are planning for the eclipse of the Sun on September 22. Although the eclipse will only be partial over Britain, it will undoubtedly be watched by many people, and the Ministry of Health is worried about possible damage to the eyes. Ophthalmologists say that solar eclipses are notorious for the damage they cause, and some time ago the Ministry of Health asked the Institute of Ophthalmology to suggest the best way of looking at the forthcoming event. Professor R. A. Weale at the institute has tackled the problem by estimating by how much the radiant energy from the Sun needs to be reduced to make it safely visible. He came to the conclusion that a filter of density $4 \cdot 5$, which passes one part in 30,000 of the incident energy, would be suitable. Presumably the Ministry of Health will make an announcement along these lines nearer the date of the eclipse; it will certainly want to discourage people from using potentially dangerous methods of looking at the Sun, such as imperfectly smoked glass or pinholes.

None of the phenomena associated with a total eclipse will be visible from Britain on September 22 . Russian astronomers are more fortunate, however, in that the path of the total eclipse will pass across the USSR, east of the Ural Mountains, and preparations for the event are under way (Nature, 216, 950: 1967). The Russians seem to have been particularly enterprising during the total eclipse of February 1961, which passed over the Crimea. On that occasion Soviet scientists, using cloud seeding techniques, were able to disperse a continuous cloud cover at designated places so that the eclipse could be observed. They will presumably be prepared to do this again if weather conditions are unfavourable. British astronomers, on the other hand, will have to wait 30 years for the next 
total eclipse visible from the British Isles. This will pass over Cornwall on August 11, 1999.

\section{European Space Marks Time}

THE much heralded European Space Conference (ESC) of Ministers in Bonn in July has now been postponed to an indefinite date in the autumn. Originally it was to have taken place "as early as possible in 1968", because much hangs on the policy decisions it is intended to take. These include the future activities of ESRO (the European Space Research Organization) and ELDO (European Launcher Development Organization) and whether these can be co-ordinated along the lines of the Causse Report (see Nature, 21\%, 1089; 1968). The European position on next year's renegotiation of the Intelsat agreement for a world network of space telecommunications and the level of European participation in various other types of application satellite were also to be discussed. It now seems probable that the European Space Conference will not only be late but limited. The British Government's decision to withdraw from ELDO at the earliest moment that is legally possible, and to have nothing to do with the Eurovision TV satellite, is likely to require so much reassessment and re-allocation of responsibilities in the short term that there will be little time left for long-term planning. This would be a mistake and an expensive one. The main trouble with joint European space projects is that ill-defined projects have been adopted too hastily and that long-term aims have been insufficiently assessed.

The decision to postpone the July meeting of the ESC in Bonn was taken at a meeting of the ESC Alternates (government officials) in Paris on May 10. From this meeting it also became clear that the British Government's analysis of the value of ELDO and the Causse Report was not shared by Britain's continental partners. The five other European members of ELDO are the ones that count. They are also members of ESRO and the effective members of CETS (Conference Européen pour Telecommunications par Satellite). All favoured the continuation of ELDO and the TV satellite as recommended by the Causse Report, and effectively rejected the British view. None of them adopted the British view of "cost effectiveness" in assessing the value of the Causse proposals. Thus they are prepared to support ELDO capital investment as an act of faith towards as yet uncertain dividends in the future. This apparently includes shouldering Britain's 27 per cent share of ELDO's costs from 1970 or so.

Meanwhile, ESRO, which in its present form Britain alone supports wholeheartedly, needs a satellite success to justify its continued existence. Its credibility has been severely dented by the recent cancellation of its major projects, the TD 1 and 2 satellites. Experimenters are well aware that simple space scientific experiments can be launched for less money and with half the trouble and delay by national programmes than by ESRO. They look therefore to ESRO only for the complex spacecraft which require a large launcher as yet beyond European scope. ESRO therefore needs a satellite success to demonstrate its ability. ESRO's first satellite was due last spring, but due to a complication of troubles a second attempt was scheduled for last Friday. Now launch of this satellite is postponed indefinitely for "technical reasons". ESRO says the delay is caused by difficulties in the third stage of the American Scout launcher. There is evidence, however, that the British-built satellite and its tape-recorder have not been working faultlessly. If the ESRO satellite misses its launch window and has to join the queue behind various American operational launches for the second time, ESRO will again have lost face.

\section{Safety in the Air}

THE standards of safety rea, hed by British airlines are significantly worse than those of airlines in the United States, or in Australia. This disquieting conclusion, already known in qualitative terms, has been put on a quantitative basis this week by a joint review by the Director of Aviation Safety and the Air Registration Board, assisted by two independent advisers (The Safety Performance of United Kingdom Airlines, HMSO, $8 s .6 d$.). There are a number of ways of measuring airline safety, none of them entirely satisfactory; but on the basis of the number of notifiable accidents per 100,000 stage flights, the United Kingdom scores $2 \cdot 62$, against $2 \cdot 03$ for France, 0.96 for Australia and 1.41 for the United States. The fatal accident record, a less reliable record because fatal accidents occur too rarely to be statistically significant, shows a similar trend. France and the United Kingdom show 0.47 and 0.43 respectively, while the United States at 0.18 and Australia at 0.09 are significantly better. Australia's performance, in particular, is startlingly good, and the report draws some lessons from it.

The review was begun after two fatal accidents involving DC 4 aircraft operated by British firms; one took place in Perpignan, the other in Stockport. But the conclusions reached by the report on the question of older aircraft are reassuring; safety records do not seem to show a decline as the aircraft ages. Such declines as there are are almost certainly caused by changes in the type of use-non-scheduled operation and smaller airlines, who use older aircraft, show worse accident records. Some aircraft seem to improve with age-the Comet 4 and the Viscount, for example, show records which have improved during the years in service. The Boeing 707 , on the other hand, after six years in service is beginning to show a worsening accident rate. One surprising conclusion is that new aircraft take a very long time to settle down to a steady accident rate. As many as two million hours of experience can elapse before the full safety potential of a new aircraft is realized-this means that if 100 aircraft are built, and each flies 3,000 hours a year, it takes six years for the "learning" period to be completed.

The report makes a number of recommendations. The most important is that the staff responsible for inspection should be brought up to full strength. Sir Frederick Brundrett, one of the independent advisers, puts it most strongly in a note in the report-"If the approved system of supervision is agreed to depend on a programme of inspections, it is quite absurd to think that this can be properly carried out without adequate staff of the right calibre". The Flight Operators Inspectorate, for example, has never been at more than half strength, and the Civil Aviation Flying Unit is 